\title{
Influência dos Pares e Educação por Pares na Prevenção à Violência no Namoro
}

\author{
Karine Brito dos Santos \\ Universidade de Brasília, DF, Brasil.
}

\author{
Sheila Giardini Murta \\ Universidade de Brasília, DF, Brasil.
}

Resumo: A literatura aponta que a influência dos pares desempenha um papel importante na compreensão da violência no namoro, e que o uso de educadores ou líderes de pares para encorajar comportamentos saudáveis entre adolescentes tem sido um componente comum em programas preventivos dessa natureza. Por meio de uma revisão narrativa, o presente artigo buscou sumarizar aspectos teóricos relativos à influência dos pares no contexto da violência no namoro, bem como descrever estudos com foco na prevenção à violência no namoro, os quais utilizaram, no todo ou em parte, a estratégia da educação por pares como componente no desenho dessas intervenções. Ao final, são discutidos pontos fortes e limitações dos programas de prevenção à violência no namoro baseados na educação por pares, além de apontar horizontes futuros de pesquisa na área.

Palavras-chave: Prevenção, Violência no Namoro, Influência dos Pares, Educação por Pares.

\section{Peer Influence and Peer Education in Dating Violence Prevention}

Abstract: Literature points out that peer influence plays an important role in the understanding of dating violence, and that the employment of peer educators or peer leaders to encourage healthy behaviors among adolescents has become a common component of such preventive programs. By means of a narrative review, this article aimed to summarize the theoretical aspects of peer influence in this context, as well as to describe studies that have focused in the prevention of dating violence and that have adopted peer education strategies, be it solely or incorporated to others in the design of the interventions. Finally, the strong suits and limitations of dating violence prevention programs based in peer education are discussed, as well as future perspectives for research in the field.

Keywords: Prevention, Dating Violence, Peer Influence, Peer Education. 


\title{
Influencia de los Pares y la Educación entre Pares en la Prevención de la Violencia en el Noviazgo
}

\begin{abstract}
Resumen: La literatura sugiere que la influencia de los pares juega un papel importante en la comprensión de la violencia en el noviazgo, y que el uso de educadores o líderes de pares para fomentar conductas saludables entre los adolescentes ha sido un componente común en los programas de prevención de este tipo. A través de una revisión narrativa, el presente trabajo pretende resumir los aspectos teóricos relativos a la influencia de los pares en este contexto, así como describir los estudios con un enfoque en la prevención de la violencia en el noviazgo, que utilizan, en su totalidad o en parte, la estrategia de educación de pares como un componente en el diseño de estas intervenciones. Al final, se discuten las fuerzas y limitaciones de los programas de prevención de la violencia en el noviazgo basada en la educación entre iguales, mientras que se señala la identificación de futuros horizontes de la investigación en el área.

Palabras clave: Prevención, Violencia en el Noviazgo, Presión de Pares, Educación entre Pares.
\end{abstract}

\section{Introdução}

A violência no namoro, referida na literatura como dating violence, foi por muito tempo negligenciada enquanto possível forma de relação abusiva presente nos relacionamentos íntimos de adolescentes, e é um fenômeno relativamente pouco estudado se comparado com a violência entre parceiros íntimos adultos. Embora seja um problema comum, pesquisas nessa área ganharam relevo, sobretudo nos Estados Unidos e no Canadá, na década de 1980, evidenciando a necessidade de reconhecer e considerar a existência de violência durante esse período da vida (Makepeace, 1981).

No cenário internacional, a preocupação social com a violência no namoro tem sido crescente em razão da alta prevalência entre adolescentes, o que torna essa questão um substancial problema de saúde pública (Anacona, 2008). Dentre as graves consequências, observam-se efeitos relacionados ao abuso de álcool e drogas, tabagismo, transtornos alimentares, comportamentos sexuais de risco, redução do bem- estar emocional e da autoestima, estresse, depressão e suicídio (Ackard, Eisenberg, \& Neumark-Sztainer, 2007; Banyard, \& Cross, 2008).

Os fatores de risco associados a essa problemática dizem respeito a experiências prévias de vitimização e exposição à violência, tais como: ter pais que são violentos um com o outro, ser vítima de maus-tratos pelos cuidadores, ter amigos engajados em relações violentas e aceitação e justificação da violência como algo possível e natural entre os parceiros. Observa-se ainda a influência potencial de pares que reforçam mutuamente conversas e comportamentos agressivos (Capaldi, Dishion, Stoolmiller, \& Yoerger, 2001) e fomentam atitudes conservadoras e estereótipos de gênero que legitimam a violência (Adelman, \& Kil, 2007).

A compreensão da violência no namoro entre adolescentes torna-se crítica ao considerar que os hábitos violentos no decorrer dessa fase da vida podem servir de base para a violência entre parceiros íntimos adultos. Esta questão se agrava ainda mais ao se levar em conta que ambos, homens e mulheres, podem ser tanto vítimas quanto perpetradores da violência na relação de namoro. Ademais, os adolescentes geralmente têm dificuldades de perceber a agressão no namoro como algo prejudicial ao relacionamento e, não raro, tendem a reconhecer comportamentos controladores e ciumentos como sinal de amor (Arriaga, \& Foshee, 2004; O'Keefe, 2005).

No Brasil, a violência no namoro entre adolescentes é considerada um fenômeno de alta magnitude. Em pesquisa organizada pelo Centro Latino-Americano de Estudos da Violência e Saúde Jorge Careli da Fundação Oswaldo Cruz, realizada em escolas públicas e privadas de dez capitais brasileiras, com 3.205 jovens entre 15 e 19 anos, observou-se que $86,9 \%$ dos adolescentes já foram vítimas e $86,8 \%$ já foram perpetradores de algum tipo de violência, física, sexual ou psicológica, durante relacionamento atual ou o último existente. Além disso, $76,6 \%$ dos adolescentes, homens e mulheres, são ao 
mesmo tempo vítima e autores de diferentes formas de agressão, sendo a violência verbal a de maior prevalência, seguida da violência sexual, da ameaça, da violência física e da violência relacional (Oliveira, Assis, Najaine, \& Oliveira, 2011).

Um estudo nacional pioneiro na exploração de fatores de risco associados à influência dos pares sobre processos de agressão no namoro foi realizado por Antônio, Koller e Hokoda (2012). Em uma amostra de 43 adolescentes de rua, de 13 a 17 anos de idade, os autores buscaram saber se testemunhar abuso de pares com relação ao parceiro no namoro pode aumentar o efeito da vitimização sobre a agressão, considerando que a literatura aponta a vitimização no namoro como fator preditor da agressão no namoro para esses adolescentes de rua. Os autores se interessaram pelo envolvimento dos pares nesse processo de agressão no namoro, tendo em vista que na maior parte do tempo os jovens estão com seus pares nas ruas. Ademais, estudos prévios revelaram que cerca de $80 \%$ deles já presenciaram em suas comunidades violência perpetrada por parceiro íntimo, $49 \%$ já testemunharam essa realidade na família e $46 \%$ já estiveram expostos a tais situações no seu grupo de pares (Ruzany et al., 2003 citado por Antônio et al., 2012).

Por meio de regressão múltipla, os autores investigaram se a vitimização no namoro prediz a agressão no namoro, identificando se o envolvimento dos pares em agressão no namoro era capaz de moderar a relação entre a vitimização e a agressão. Os resultados sugeriram que a agressão foi significativamente predita pela vitimização, sendo que o envolvimento dos pares em agressão no namoro atuou como moderador dessa relação, embora não tenha sido capaz de predizer de modo significativo a agressão no namoro. Observou-se que, quanto mais frequentemente os jovens eram vitimados em conflitos no namoro, mais frequentemente eles abusavam de seus parceiros no namoro, demonstrando que ter pares envolvidos em agressão no namoro exacerba os efeitos da vitimização sobre a agressão em situações de namoro. Segundo os autores, intervenções preventivas com foco na prevenção à violência no namoro, voltadas para adolescentes de rua, devem ser sensíveis às experiências de vitimização dos jovens perpetradores de agressão no namoro, e buscar ajudar aqueles jovens que presenciaram abuso de pares em relações de namoro, não focando somente na redução do envolvimento dos pares em agressão no namoro.
O enfrentamento da violência no namoro entre adolescentes torna-se premente (Njaine, Oliveira, Ribeiro, Minayo, \& Bodstein, 2011), tendo em vista que inexistem no Brasil programas preventivos com evidências robustas de eficácia e efetividade (Murta, Santos, Martins, \& Oliveira, 2013a; Murta, Santos, Nobre, Araújo, \& Miranda, 2013b) e raramente os adolescentes procuram ajuda para lidar com experiências de violência nas relações afetivas. Ao estudar uma amostra de 283 adolescentes do ensino médio de escolas públicas e privadas, Soares, Lopes e Njaine (2013) identificaram que apenas $5 \%$ dos adolescentes buscaram ajuda para problemas em decorrência de violência nas relações de namoro e do "ficar", sendo que somente $3,5 \%$ solicitaram ajuda profissional, notadamente em função de problemas emocionais. Em geral, os adolescentes procuram o apoio dos amigos para compartilhar experiências e ouvir opiniões sobre problemas nas relações afetivo-sexuais, pois se sentem mais à vontade para falar com os amigos do que com os pais, já que estes vivenciam situações semelhantes no namoro por estarem no mesmo período da vida. A preferência de contar com os amigos para trocar informações e desabafar, na condição de confidentes e conselheiros, está relacionada também com a falta de espaço nas famílias e as dificuldades de comunicação com os pais em função da diferença geracional e por vergonha ou medo, além da presença de temas tabus e comportamentos considerados errados e proibidos pelos pais.

Embora avaliem em primeiro lugar os familiares como sendo os mais indicados para ajudá-los em situações de violência nas relações afetivas $(35,4 \%)$, seguido dos amigos (28,2\%), dos profissionais de saúde $(10,7 \%)$, dos educadores $(1,1 \%)$ e dos profissionais religiosos $(0,4 \%)$, na prática há uma contradição, pois, dos adolescentes que buscaram efetivamente auxílio nesses casos, $51,5 \%$ procuraram amigos e $36,7 \%$ recorreram a familiares como principais fontes de ajuda e somente $12,1 \%$ procuraram apoio dos profissionais de saúde. É importante assinalar ainda diferenças por sexo, com os meninos $(6,5 \%)$ menos propensos a buscar ajuda de profissionais do que as meninas $(13,4 \%)$, todavia, dentre as pessoas mais indicadas para ajudar, os meninos se referiram mais aos amigos $(39,8 \%)$ do que as meninas $(20,9 \%)$. Já no tocante às diferenças entre alunos de escolas públicas e privadas, observou-se que os alunos da rede pública se referiram mais aos familiares $(41,6 \%)$ do que os da rede privada (27,8\%) (Soares et al., 2013). 
O fomento de medidas de prevenção no intuito de aumentar o comportamento de ajuda, tanto no sentido de buscar apoio quanto no de oferecer auxílio nesses contextos, requer, segundo Soares et al. (2013), mudanças na forma de se pensar o sistema de atenção à saúde quanto à prevenção à violência e promoção de saúde com vistas o desenvolvimento de relações saudáveis. O mapeamento da rede de apoio e busca de ajuda dos adolescentes permite não somente pensar em estratégias de prevenção à violência, como também traz elementos ricos para ajudar a superar algumas dificuldades na implementação de programas de prevenção, por exemplo, a preocupação dos adolescentes com a proteção e a privacidade de suas relações amorosas; a valorização da autossuficiência, a falta de informação dos adolescentes para avaliar a qualidade do namoro e, ainda, o estigma relacionado ao ato de buscar ajuda para lidar com problemas pessoais. Evidencia, sobretudo, a necessidade de busca ativa e intervenção precoce nessa população-alvo, promovendo acesso aos serviços de saúde, apoio e diálogo aberto, estimulando comportamentos de busca de ajuda entre adolescentes envolvidos em situações de violência no namoro.

Tornar as relações de namoro mais saudáveis, a fim de evitar, minimizar ou eliminar a violência e os seus impactos danosos na saúde física, mental e sexual dos adolescentes, tem sido, portanto, uma preocupação crescente em estudos e programas de prevenção primária e secundária com foco na violência no namoro. A prevenção primária refere-se às ações preventivas dirigidas a toda população, no intuito de reduzir a incidência, diminuindo a ocorrência de novos casos. Quando a intervenção é oferecida para uma população que apresenta sinais inicias de dificuldades ou transtornos, trata-se de prevenção secundária. Já a prevenção terciária, consiste na intervenção para aqueles que apresentam transtorno com diagnóstico definido (Dalton, Elias, \& Wandersman, 2007). Considerando a interação dinâmica e complementar das estratégias de promoção, prevenção e tratamento, há ainda três níveis de prevenção de acordo com o modelo integrativo proposto por Weisz, Sandler, Durlak e Anton (2005): 1. Prevenção universal: englobam intervenções cuja abordagem aos fatores de risco é dirigida a toda população; 2. Prevenção seletiva: refere-se a intervenções desenhadas para atingir grupos que compartilham fatores de risco significativos; 3 . Preven- ção indicada: estratégia voltada para indivíduos que possuem sintomas significativos de uma desordem, embora não reúnam critérios de diagnóstico.

A prevenção primária à violência no namoro no Brasil ainda é incipiente. Em revisão de literatura realizada por Murta et al. (2013a), foram identificados 19 artigos publicados entre 1992-2010, totalizando 15 estudos com descrição e avaliação de intervenções de prevenção primária à violência no namoro voltada para adolescentes. Nesse levantamento, observou-se predominância de programas implementados na América do Norte (80\%) e na Europa (13\%), com identificação de apenas um estudo na América Latina (7\%), realizado no México. As intervenções com foco na prevenção à violência no namoro são de caráter universal, de duração breve e de base escolar, abordando conteúdos relativos ao manejo das emoções e resolução de conflitos; a construção de habilidades sociais; além de informações sobre violência no namoro e questões sobre os papéis tradicionais de gênero. Há evidências de eficácia dos programas de prevenção à violência no namoro em alguns estudos, com resultados consistentes obtidos por meio de mudanças em variáveis comportamentais e cognitivas.

A escassez de pesquisas no Brasil é notória, com publicação de poucos trabalhos ainda em fase inicial com foco no desenvolvimento de intervenções preventivas (Murta et al., 2011; 2013b) e alguns estudos de cunho descritivo sobre o tema. Murta et al. (2013a) apontam para a necessidade de expansão na área, tendo em vista a baixa produção nacional, destacando a importância da avaliação de necessidades e da avaliação de processo, no intuito de monitorar a qualidade das intervenções durante a sua execução, observando possíveis fatores preditores de sucesso ou fracasso. A elaboração de programas multicomponentes de prevenção à violência no namoro entre adolescentes, a serem implementados em escolas do ensino fundamental ou médio, focados no ensino de habilidades é desejável em detrimento de intervenções de estritamente informativas, englobando competências capazes de diminuir o impacto de diferentes fatores de risco, a nível individual (déficits em habilidades sociais), familiar, cultural e relativo aos pares.

Embora nos anos recentes tenha havido um aumento expressivo de pesquisas sobre violência no namoro, notadamente no cenário internacional, 
a literatura tem apontado a necessidade de dar atenção ao desenvolvimento metodológico e teórico de estratégias de prevenção, as quais incorporem em seu desenho, componentes significativos para o desenvolvimento de habilidades sociais dos adolescentes, além de integrar aspectos relacionados à cultura e influência de pares (Cornelius, \& Resseguie, 2007; Shorey et al., 2012).

As evidências de que a interação entre os pares pode ser educacionalmente efetiva têm sido amplamente discutida na literatura ao longo das últimas décadas (Backett-Milburn, \& Wilson, 2000). Segundo Weisz e Black (2010), a educação por pares tem apresentado benefícios consistentes, ao aumentar o potencial de mudança de comportamento, fornecer modelos de papéis confiáveis e empoderar a audiência e os adolescentes líderes, razão pela qual tem sido considerada por muitos como uma estratégia de ponta à prevenção da violência no namoro. O presente artigo apresenta uma revisão crítica da literatura com três objetivos: 1 . Sumarizar aspectos teóricos relativos à influência dos pares no contexto da violência no namoro; 2 . Descrever estudos empíricos que tiveram como foco a prevenção à violência no namoro, os quais utilizaram, no todo ou em parte, a estratégia da educação por pares no desenho do programa; 3. Apontar horizontes futuros de pesquisa e intervenção nessa área de atuação preventiva.

\section{Influência dos pares na violência no namoro}

A influência dos pares desempenha um importante papel na compreensão da violência no namoro (Foshee et al., 2013). Ao investigarem o papel dos pares na emergência dos relacionamentos românticos heterossexuais na adolescência, Connolly, Furman e Konarski (2000) demonstraram como a natureza dos relacionamentos com os amigos próximos pode influenciar positivamente e negativamente características do relacionamento romântico. Esse estudo longitudinal acompanhou durante três anos uma amostra randômica de 180 estudantes de 14 anos de idade do ensino médio de uma escola pública. Os resultados sugeriram que as redes de pares criam um contexto para os relacionamentos românticos se desenvolverem, sendo que as características estruturais do grupo de pares e a participação destes nessas redes podem influenciar o momento e a emergência dessas rela- ções românticas. Ademais, os pares e os relacionamentos românticos passados ocupam um importante papel na modelação de expectativas românticas e no desenvolvimento de habilidades sociais.

Zimmer-Gembeck (2002), por outro lado, examinou como se dá a adaptação no sistema de relacionamento de pares em função do desenvolvimento de relações românticas. Segundo a autora, o desenvolvimento de relações românticas pode mudar a rede de pares e a natureza dos relacionamentos com amigos e demais, o que exige uma complexa negociação, que pode sofrer alterações em função do tempo e do aumento do envolvimento com os parceiros. As estratégias que os adolescentes usam para gerenciar e manter as relações existentes com pares mais próximos, e os relacionamentos românticos iniciais, podem ter importantes consequências para seu desenvolvimento psicossocial futuro. Manter amigos próximos pode ajudar a negociar a tarefa de desenvolvimento de relações românticas, sendo que a qualidade das amizades serve como um modelo preliminar que guia as expectativas frente às futuras relações e a busca de qualidades para os relacionamentos românticos. Nesse sentido, os amigos podem fornecer ajuda concreta para questões específicas, tais como dar conselhos a respeito da seleção do parceiro, feedbacks sobre a escolha, apoio durante conflitos e incentivo à dissolução de relacionamentos não saudáveis.

A importância crescente que os pares assumem na adolescência, segundo Leff (2004), ocorre na medida em que os jovens buscam validação, companheirismo e apoio dos pares, enquanto começam a explorar a intimidade e a compatibilidade em seus relacionamentos românticos iniciais. A autora comenta que não é de se surpreender que o grupo de pares mais próximos possa influenciar o namoro dos adolescentes, de modo positivo ou negativo, razão pela qual discutir sobre a pressão e a cultura dos pares na formação e manutenção de relações íntimas dos adolescentes torna-se fundamental.

A relação entre os pares também ocupa um papel importante na compreensão de como o conflito entre os pais pode levar à violência no namoro (Kinsfogel, \& Grych, 2004). Ao investigar as formas em que a exposição ao conflito interparental podem afetar o namoro, em uma amostra de 391 adolescentes de uma escola pública do ensino médio (205 meninas e 186 meninos, de 14 a 18 anos), os autores identificaram que jovens provenientes de lares mais agressi- 
vos tendem a se vincular com pares mais inclinados a se engajar em comportamentos abusivos, os quais podem desenvolver suas próprias normas que legitimam ou até mesmo encorajam o tratamento agressivo entre parceiros no namoro. $\mathrm{O}$ estudo demonstrou ainda que a maneira como os amigos manejam conflitos em seus próprios namoros pode ser tão relevante, ou talvez até mais importante do que como seus pais o fazem, e que a extensão na qual os pares aprovam ou desaprovam tais comportamentos abusivos, pode exercer uma forte influência sobre o comportamento do adolescente no namoro.

Para Leadbeater, Banister, Ellis e Yeung (2008), os jovens podem aprender sobre relacionamentos românticos ao observar e refletir sobre os comportamentos dos demais e, na ausência de modelos de papéis positivos, carecem de informações precisas sobre agressão no namoro e relacionamentos saudáveis. Os autores examinaram os efeitos das práticas parentais vivenciadas pelos adolescentes e da agressão e vitimização por pares, sobre os seus relatos de agressão e vitimização no namoro, em uma amostra de 149 adolescentes (51 meninos e 98 meninas, de 12 a 18 anos), que estavam em relações de namoro na ocasião. Os resultados apontaram que o monitoramento parental pode ser considerado um fator protetivo com relação ao uso de agressão relacional contra o parceiro no namoro. Ademais, as normas sobre o emprego de comportamentos agressivos nas interações com os pares não raro serviam para justificar seu uso em relações românticas.

O estudo de Leadbeater et al. (2008) sugeriu ainda que diferentes aspectos dos comportamentos dos pares e dos pais são relevantes no aumento ou diminuição do risco para diferentes tipos de vitimização e agressão relacional no namoro. Por exemplo, se os jovens usam agressão relacional no manejo dos pares de amizade, é provável que tenham elevadas expectativas de controle e exclusividade nas relações de namoro, estando particularmente vulneráveis a se sentir vitimados quando o parceiro se engaja em atividades com os outros, tenta fazê-los sentir ciúmes ou não lhes dá atenção.

A literatura aponta que os pares não somente modelam atitudes sobre a violência no namoro, mas geralmente servem como primeiro canal de conselho para amigos que buscam auxílio em razão de abuso (Soares et al., 2013). Os adolescentes tendem a revelar suas experiências para os pares, sendo mais hesitantes em envolver os pais em discussões sobre violência no namoro. Os amigos são identificados como fontes de suporte por vítimas e perpetradores, sugerindo uma preferência em receber ajuda do grupo de pares nesses casos. Contudo, observa-se que os adolescentes necessitam de mais orientação sobre como responder apropriadamente a dificuldades de amigos em situação de violência no namoro, bem como encorajar vítimas a buscar ajuda de profissionais (Rizzo, 2009).

Por serem não raro os únicos a tomar conhecimento de que a violência no namoro está acontecendo, a resposta dos pares a esse tipo de ocorrência é muito importante, pois sem a intervenção de um espectador a vítima pode ficar muito isolada. O estudo realizado por Weisz e Black (2008) buscou investigar justamente as crenças de 202 adolescentes do ensino fundamental de uma escola pública (108 meninas e 94 meninos, de 12 anos de idade), sobre a possibilidade de intervenção de pares em situações de violência no namoro. As crenças dos jovens foram analisadas à luz do modelo situacional de intervenção do espectador em situações de emergência proposto por Latané e Darley (1968), levando em conta os três últimos estágios de tomada de decisão quanto à possibilidade de intervir: 1. Consciência - perceber se alguém precisa de ajuda; 2. Definição - decidir se a situação deve ser considerada uma emergência; 3. Responsabilidade - decidir quem é responsável por responder à emergência; 4 . Plano/ autoeficácia - formulação do plano para ajudar, envolvendo a decisão do espectador sobre a sua capacidade de executá-lo.

Após assistirem uma breve vinheta que incita a intervenção dos pares em uma situação de violência no namoro, Weisz e Black (2008) perguntavam aos adolescentes as seguintes questões: 1 . O que acontece entre duas pessoas em uma relação diz respeito somente a eles? 2. Você se envolveria? 3. O que você faria? Os resultados sugeriram que comumente a situação de violência no namoro é vista pelos adolescentes como algo privado, no qual não deveriam intervir e, caso optem por fazê-lo, o envolvimento nesses casos dependeria da gravidade da violência. Os adolescentes demonstraram ter clareza da responsabilidade de responder em tais situações, no sentido de interromper o agressor e proteger a vítima. E, quanto à percepção de autoeficácia para intervir, os adolescentes apresentaram preocupações sobre a possibilidade de que algo possa dar errado, 
que eles possam ficar em apuros, causar problemas, dar conselhos errados e até mesmo se machucar. Dentre os planos de ação, mencionaram a ideia de conversar com o agressor, ouvir a vítima, buscar ajuda de um adulto ou conselheiro, contar para a mãe, falar para alguém capaz de lidar com essa situação e chamar a polícia (Weisz, \& Black, 2008).

Para Weisz e Black (2008) não é de se surpreender que os adolescentes possam se sentir inseguros sobre se e como deveria intervir nesses casos, razão pela qual o ensino de habilidades de ajuda pode auxiliá-los no sentido de evitar ignorar ou intervir de modo perigoso ou agressivo, aumentando a intenção e capacidade de intervir de modo seguro e efetivo nesses contextos.

Em estudo experimental de natureza similar, Ruiz, Expósito e Bonache (2010) investigaram as reações de 98 adolescentes (51 meninos e 47 meninas, de 15 anos de idade), ao serem testemunhas de um episódio de violência contra uma amiga. Foram examinadas diferenças nas reações em função do sexo do espectador, familiaridade com o agressor (estranho $\mathrm{x}$ amigo), tipo de relação entre o agressor e a vítima (ficante x parceiro), bem como a influência de crenças sexistas (hostis $\mathrm{x}$ benevolentes) do espectador em tais respostas. Os resultados apontaram maior resposta de evitação das meninas frente à violência entre parceiros românticos do que em "ficantes". Já os garotos revelaram reações mais negativas quando a vítima mantém relação com o agressor, do que no caso de uma "ficada", sobretudo se o agressor é desconhecido. No que tange os efeitos do sexismo ambivalente, observou-se que o sexismo hostil tende a aumentar reações negativas.

Clarear os fatores que influenciam as respostas dos adolescentes diante de conflitos no namoro é uma preocupação bastante recente na literatura. Sullivan et al. (2012) identificaram os fatores que influenciam as respostas dos adolescentes diante de situações de problema no namoro, considerando aspectos individuais, familiares e relativos aos pares, ao entrevistar 38 jovens, 23 meninas e 15 meninos. Os autores argumentam que esses diferentes fatores podem servir de suporte e/ou barreiras, tornando mais fácil ou mais difícil a resolução de problemas no namoro.

Dentre os aspectos favoráveis às melhores respostas dos adolescentes diante de situações de violência no namoro, na esfera individual, foram observadas características pessoais e confiança na habilidade de lidar com problemas no namoro, habilidade de autorregulação das emoções, crenças e valores que influenciam as interações com pares e com o parceiro, bem como fatores situacionais (experiências prévias e antecipação das consequências). No que tange os fatores relacionados aos pares, os adolescentes abordaram o aconselhamento de apoio dos pares, a vontade dos pares para se envolver em problemas de namoro e a observação das relações de namoro dos pares. $\mathrm{Na}$ esfera familiar, observou-se suporte, conselhos e mensagens sobre relacionamentos de membros da família, os quais são tidos como modelos para os adolescentes (Sullivan et al., 2012).

Dentre as barreiras para a resolução de problemas no namoro, observou-se, no nível individual, dificuldades de regulação da raiva, ansiedade e tristeza, reservas em compartilhar sentimentos, pensamentos e/ ou experiências, bem como a influência de experiências prévias e consequências potenciais em resposta a situações de problema no namoro. A influência dos pares se fez presente em mensagens confusas ou conselhos não apoiadores, conflitos entre parceiros no namoro instigados por pares, agressão baseada nos pares, normas de namoro dos pares e modelos de relações de namoro. No que diz respeito à família, os adolescentes evidenciaram a percepção de falta de apoio ou aconselhamentos inúteis de membros da família, além do envolvimento familiar nas relações de namoro (Sullivan et al., 2012).

Especificamente quanto ao apoio dos pares, Adams e Williams (2011) investigaram a influência dos pares na tomada de decisão e resolução de problemas, ao identificar o que os adolescentes consideram importante para oferecer como conselho para outros adolescentes sobre namoro. Em uma amostra de 75 adolescentes, com recorte de gênero e etnia, os autores observaram através de grupos focais que os adolescentes naturalmente dirigiram conselhos para adolescentes do mesmo sexo, sendo que as mulheres ofereceram cerca de três vezes mais conselhos do que os homens e, com mais frequência, relataram experiências pessoais e mantinham um diálogo colaborativo, em que pese o fato de no diálogo entre as mulheres haver mais referências negativas sobre os homens do que o contrário.

Os conselhos dos adolescentes emergiram ao longo de uma linha do tempo que reflete os períodos ou fases do relacionamento - início, manutenção e término, abordando temas centrais sobre 
questões de gênero e sexualidade. Os conselhos oferecidos na fase de iniciação englobaram considerações pré-namoro, notadamente quanto à seleção do parceiro, as pretensões e circunstâncias sob as quais alguém deve ou não namorar, a procura e o timing. Dentre os conselhos oferecidos nessa etapa, os adolescentes recomendaram buscar ser amigo da pessoa antes de decidir namorá-la, não permitir os amigos influenciarem muito sobre quando e quem namorar, pensar na qualidade do relacionamento potencial e nas características desejáveis do namorado antes de se envolver romanticamente, além de conselhos sobre condições a serem evitadas, por exemplo, o envolvimento romântico que não faz bem para a pessoa ou quando a relação não é correspondida, podendo gerar possíveis embaraços em caso de rejeição (Adams, \& Williams, 2011).

Na fase de manutenção, os conselhos dos pares giraram em torno de preocupações dentro de um relacionamento estabelecido, tais como: a tendência a ficar muito preso em compromisso nesse momento de suas vidas; de não se deixar levar pelos sentimentos românticos; o medo de eventual perda e dor; a avaliação do risco de estar em um relacionamento e a importância de ter uma fonte mais estável de apoio mantendo os amigos por perto; a recomendação de agir com cautela em caso de risco social e emocional; a necessidade de conhecer a si mesmo e desenvolver confiança, estabelecendo limites e respeitando-os; o pensar cuidadosamente sobre o envolvimento em atividade sexual, sobretudo diante da influência dos amigos, do namorado e da possível perda da dignidade pessoal. Ademais, os adolescentes abordaram questões de controle e de poder no tocante a posse do parceiro, com pressão dos pares no sentido dos meninos não parecerem "amarrados" e das meninas não darem a impressão de que são ciumentas e pegajosas (Adams, \& Williams, 2011).

$\mathrm{Na}$ fase de término, os conselhos dos pares refletiram as condições sob as quais um namoro deve ser rompido ou como efetivamente proceder depois de terminar a relação. Observou-se uma minimização dos conselhos sobre rompimento, sendo que as recomendações oferecidas eram reflexos de experiências prévias sofridas, em consequência de relações amorosas desfeitas. Os adolescentes aconselharam a como lidar com o término do relacionamento e quando seguir em frente, sugerindo não se tornar excessivamente perturbado em caso de eventual perda do relacionamento, buscar manter a mente ocupada como uma estratégia para não ficar pensando no ex-parceiro, evitando resultados negativos depois de uma separação romântica. Embora fosse pouco frequente o conselho para romper a relação, os adolescentes recomendaram deixar o parceiro se ele ou ela colocá-la(o) para baixo ou se não for leal (Adams, \& Williams, 2011).

De modo geral, os adolescentes espontaneamente buscaram antecipar a resolução de problemas relativos a cada estágio ou fase do namoro, enfatizando o desenvolvimento de relações românticas na adolescência como um processo estressante. Os autores destacaram a importância de capacitar os adolescentes com ferramentas e confiança para tomar decisões informadas antes, durante e após o término de relações românticas, a fim de aumentar a percepção da competência pessoal no estabelecimento de parcerias íntimas (Adams, \& Williams, 2011). Ensinar os adolescentes a distinguir e utilizar de modo útil os conselhos no manejo de problemas no namoro parece ser relevante tanto na compreensão do papel dos pares no desenvolvimento, manutenção e proteção em casos de violência no namoro, quanto na promoção de relações saudáveis.

A literatura sugere ainda que aprender habilidades específicas para conduzir interações difíceis nos relacionamentos, ao modo da habilidade de resistência aos pares, pode ser útil para evitar uma gama de comportamentos prejudiciais à saúde, no contexto de relação entre pares, seja de amizade ou de namoro (Wolfe, Crooks, Chiodo, Hughes, \& Ellis, 2012). Em uma amostra randômica de 196 estudantes, 86 meninos e 110 meninas, os autores avaliaram no pós-teste habilidades de resistência aos pares mediante uma intervenção baseada no paradigma role play, com um currículo de 21 aulas, e foco no ensino de habilidades de relacionamento para o manejo de cenários desafiantes no contexto dos pares e do namoro. Os resultados sugeriram a existência de respostas específicas de resistência positiva (negociação, adiamento e recusa) e negativa (complacência, consentimento) aos pares, bem como respostas globais associadas ao questionamento de opiniões, solicitação, comunicação e eficácia percebida. Estudantes que receberam a intervenção foram menos propensos a ceder à pressão negativa dos pares e mais propensos a demonstrar habilidades de negociação, estando mais inclinados a usar respostas de adiamento, se comparados ao grupo controle. 
Identificar fatores de risco e fatores de proteção (Vagi et al., 2013) e aspectos moderadores e/ ou mediadores da violência no namoro (Miller, Gorman-Smith, Sullivan, Orpinas, \& Simon, 2009; Olsen, Parra, \& Bennett, 2010), nos mais variados domínios bioecológicos, parece ser um caminho promissor para alcançar a compreensão sobre o papel da influência dos pares na gênese da violência no namoro. Pode ainda servir de subsídio no desenho, implementação e avaliação de programas prevenção diretamente interessados na influência potencialmente positiva e/ou negativa que os pares exercem sobre o comportamento dos adolescentes no namoro.

Essa visão panorâmica da literatura indica que o foco na influência dos pares pode ser um terreno fértil para a elaboração de intervenções preventivas consistentes, capazes de mudar o contexto no qual as atitudes e habilidades individuais funcionam (Kinsfogel, \& Grych, 2004). Embora a influência dos pares nas relações de namoro tenha sido amplamente investigada no exterior, na literatura nacional o estudo desse tema é incipiente (Antônio et al., 2012; Soares et al., 2013). Se o uso de educadores de pares para encorajar comportamentos saudáveis parece ser altamente benéfico, a busca de evidências de eficácia que suportem a educação por pares como estratégia de prevenção à violência no namoro é um campo ainda a ser explorado.

\section{Prevenção à violência no namoro com base na educação por pares}

Programas de educação por pares são baseados na suposição de que a influência dos pares é um fator importante na mudança de comportamentos, crenças e atitudes que suportam a violência no namoro. Intervenções dessa natureza não raro envolvem os pares, direta ou indiretamente, como componente chave no desenho, implementação e avaliação desses programas. Em geral, os educadores/líderes de pares são treinados para ensinar ou serem cofacilitadores (com adultos) de grupos e atividades, provendo orientação e auxílio aos pares (Foshee, \& Langwick, 2010).

Embora a educação por pares seja apontada como uma ferramenta de ponta na prevenção da violência no namoro entre adolescentes (Weisz, \& Black, 2010), pesquisas baseadas em evidências com foco específico nesse componente ainda são escassas na literatura nacional (Murta et al., 2013a), razão pela qual o detalhamento de um relato de experiência e os resultados de quatro estudos empíricos com esse fim será apresentado a seguir.

A experiência de conselheiros de pares que participaram de um programa de prevenção à violência no namoro foi o alvo de interesse de Paciorek, Hokoda e Herbst (2003). Nesse estudo, que entrevistou nove educadores de pares do ensino médio, de 15 a 18 anos, buscou-se conhecer as habilidades aprendidas a partir do programa, os sentimentos dos adolescentes enquanto faziam apresentações, bem como o impacto da participação deles na vida pessoal. Os autores apontaram que em muitas entrevistas ocorreram autorrevelações, sendo que um relatou ter perpetrado e três estudantes declararam ter sido vítima de violência no relacionamento. Dois estudantes relataram aumento no conhecimento sobre si próprio e oito descreveram um aumento no conhecimento sobre a violência no namoro entre adolescentes. Dentre as habilidades adquiridas, a comunicação e a escuta foram as mais frequentes, seguida de habilidades em dramatizações. Ademais, o engajamento em comportamentos mais saudáveis dentro da família foi descrito por cinco estudantes. Esse estudo exploratório forneceu evidências de que o aconselhamento de pares é visto como positivo para os jovens, os quais podem fornecer sugestões úteis para melhorar a implementação do programa.

Desenhado para promover consciência, ensinar habilidades e alterar atitudes com relação à violência no namoro, o programa desenvolvido por Schwartz, Griffin, Russell e Frontaura-Duck (2006) buscou avaliar a efetividade de uma intervenção preventiva, entregue por 14 educadores de pares a 290 estudantes em um campus universitário. O programa tinha como principal objetivo aumentar a consciência sobre como os estereótipos dos papéis de gênero contribuem para a violência relacional, descobrir estratégias para evitar violência no relacionamento, identificar os vários tipos de violência relacional, e promover responsabilidade social sobre essa questão. Os educadores de pares receberam treinamento sobre facilitação e como falar em público, teoria e dinâmica da liderança, bem como conteúdos relevantes tais como álcool e drogas, agressão sexual, violência no namoro, etc.

Essa intervenção fez uso de diversos recursos: 1. Vinhetas que demonstravam a escalada do abuso psicológico e físico motivado por atitudes e scripts internos que legitimam a dominância mas- 
culina; 2. Painel de discussão no formato open-mike (pergunta-resposta), no qual a audiência tem oportunidade de questionar sobre preocupações específicas a cerca de conflitos nas relações; 3 . Aula expositiva educativa modelada após um talk show, ilustrando um diálogo aparentemente casual, no qual um homem e uma mulher apresentam fatos sobre violência na relação. Os resultados sugeriram uma diminuição nas atitudes estereotípicas e misóginas sobre a violência no namoro na avaliação realizada imediatamente após o programa (Schwartz et al., 2006).

Turner (2006), por sua vez, investigou na sua tese o papel que os pares desempenham em relações de namoro abusivas por meio do programa de prevenção primária denominado Safe Dates Theater Project (SDTP). O autor examinou se programas de prevenção à violência no namoro com base na liderança de pares são efetivos em melhorar o conhecimento dos estudantes sobre esse tema. O programa foi aplicado por meio de um currículo em uma escola pública do ensino médio. Para determinar se obteve sucesso em modificar o conhecimento e as atitudes dos estudantes foram usadas medidas de avaliação no pré-teste e pós-teste. Os resultados globais do SDTP apontaram êxito moderado em aumentar o conhecimento dos estudantes sobre relações abusivas, sugerindo ser o uso de pares uma estratégia de prevenção à violência no namoro útil para prover informações para dos adolescentes.

O Expect Respect, programa de base escolar para prevenir a violência no namoro e promover relacionamentos saudáveis e seguros em escolas do ensino médio e fundamental, também englobou a educação por pares na sua composição: o SafeTeens Youth Leaderchip. O objetivo era engajar e empoderar adolescentes para se tornar modelos positivos e atuar como líderes de pares na prevenção à violência no namoro, bullying e assédio sexual. Essa mobilização dos adolescentes líderes visa ainda aumentar comportamentos ativos de espectadores, além de ampliar a consciência a partir do uso de marketing social e mídias (Ball, Kering, \& Rosenbluth, 2009).

No SafeTeens, os jovens receberam 8 horas de treinamento e, em seguida, escolheram um problema relacionado à violência sexual e violência no namoro presente em sua escola, para desenvolver um projeto de conscientização com fins de prevenção. Os estudantes líderes foram orientados para servir como modelos de papéis e educadores de pares, bem como oferecer suporte aos pares. Os resultados globais do Expect Respect foram promissores ao demonstrar efetividade na sensibilização sobre assédio sexual e bullying, aumento da habilidade de identificação de sinais de abuso, aumento das habilidades de resolução saudável de conflito, bem como a diminuição de comportamentos de controle e insegurança nos relacionamentos. Embora haja indícios de sucesso, o programa apresentou falhas na rigorosidade da avaliação geral e específica de seus componentes, sem registros na ocasião de evidências de eficácia (Ball et al., 2009).

$\mathrm{O}$ uso de pares como facilitadores foi descrito também no estudo longitudinal de Warthe, Kostouros, Carter-Snell e Tutty (2013), que teve como objetivo desenvolver, implementar e avaliar um programa de prevenção à violência no namoro para 16 líderes de pares. O desenho do projeto piloto Stepping Up oferece um bom exemplo de como incorporar no currículo componentes individuais (riscos, vulnerabilidades, comportamentos de autocuidado), relacionais (resolução de conflito, relações saudáveis, controle e poder), comunitários (papel dos espectadores ou pares, fontes de busca de ajuda) e sociais (estereótipos de gênero, papel dos mitos).

Na fase de desenvolvimento, o Stepping Up realizou o recrutamento e treinamento de 16 facilitadores de pares, o desenvolvimento de medidas de avaliação e a elaboração do currículo, bem como o engajamento de parceiros da comunidade e do comitê de consultivo. Os professores foram solicitados a identificar e encaminhar facilitadores de pares em potencial com atitudes e habilidades consistentes com o projeto, os quais foram convidados a participar de um dos encontros informacionais oferecidos pelos pesquisadores, sendo que os estudantes interessados completaram um questionário indicando a disponibilidade em participar do programa e o interesse na violência no namoro. $\mathrm{O}$ treinamento dos facilitadores de pares ocorreu simultaneamente ao desenvolvimento do currículo e os módulos foram desenvolvidos a partir das principais questões levantadas pelos facilitadores de pares no treinamento. A primeira sessão, com duração de 6 horas, incluiu discussões sobre tipos de abuso, mitos, papéis de gênero, segurança, barreiras de comunicação, consentimento, recursos e atribuição de responsabilidade, dentre outros exercícios e atividades (Warthe et al., 2013).

As informações sobre o Stepping Up foram amplamente difundidas para todos os alunos do campus, 
pelos consultores do programa, na intranet e em associações de estudantes, com ativa atuação dos facilitadores de pares no encorajamento da participação de seus pares. As atividades do Stepping $U p$ foram entregues em um final de semana, que incluiu a realização de uma dramatização na sexta-feira à noite, dois dias de workshops (quatro módulos: relacionamentos saudáveis, relações sexuais, comunicação e limites, mídia e gênero) durante o sábado e o domingo, e metade da segunda-feira foi dedicada ao começo do planejamento dos projetos de prevenção comunitários a serem oferecidos no campus (Warthe et al., 2013).

Os resultados do Stepping $U p$ sugeriram que o aumento do conhecimento foi sustentado no follow up após 8 meses, bem como mudanças nas crenças e atitudes de violência e abuso. Embora o estudo revele limitações quanto à baixa retenção de participantes na avaliação de seguimento (nove respondentes), o feedback dos facilitadores de pares foi positivo, revelando satisfação e gratificação em participar do programa. Dentre os aspectos desafiadores desse projeto, os jovens abordaram a falta de tempo, o que levou alguns facilitadores de pares a questionar suas habilidades e conhecimentos de facilitação de grupos, dificuldades quanto à prática de facilitação, a preparação dos módulos e o planejamento das atividades, bem como a necessidade de treinamento específico para responder em situações de autorrevelação. Em que pese às limitações, as evidências são favoráveis ao uso do modelo de facilitação por pares na prevenção da violência no namoro, com ganhos expressivos para os jovens, pela oportunidade não somente de discutir esses temas, mas, sobretudo, de consolidar o aprendizado por meio de projetos comunitários de prevenção (Warthe et al., 2013).

\section{Apontamentos e horizontes Futuros}

É inconteste o papel dos pares tanto na emergência das relações românticas, quanto no desenvolvimento, manutenção e proteção em casos de violência no namoro. Alterar as respostas aos pares tem sido, portanto, uma preocupação frequente de programas de prevenção à violência no namoro, tendo em vista o fato de que estes são uma fonte primária de influência normativa para os adolescentes (Foshee, \& Langwick, 2010; Foshee et al., 2013).

Entretanto, ainda são escassos na literatura nacional (Murta et al., 2013a) estudos sobre o desenvolvimento, implementação e avaliação de programas de educação por pares baseados em evidência com foco nessa questão, ainda que esta seja considerada uma estratégia de ponta (Weisz, \& Black, 2010). Em geral, programas dessa natureza tem como ponto forte o fato de considerar a influência dos pares como um componente crítico no desenho dessas intervenções, já que estes não somente modelam atitudes sobre violência no namoro, como, não raro, são os primeiros, quando não os únicos, a tomar conhecimento dessas situações de violência. Ademais, destaca-se o esforço no sentido de fomentar o envolvimento, direto e indireto, dos educadores ou líderes nessas estratégias de prevenção, ao modo de multiplicadores ou agentes de prevenção, com potencial de prover informações e auxílio aos seus pares, aumentando a intenção e capacidade de intervir de maneira efetiva e segura nesses casos.

As informações sumarizadas nessa revisão crítica de literatura evidenciam a necessidade de avaliações mais rigorosas desses programas de prevenção. Embora os resultados dos programas apresentem indícios de que contribuíram para afetar fatores relacionados à violência no namoro, avaliar se de fato essas mudanças ocorreram torna-se uma tarefa bastante difícil, em função da ausência de dados empíricos consistentes e/ou medidas de avaliação de impacto confiáveis. Em geral, os programas de prevenção à violência no namoro com base na educação por pares necessitam de refinamento e melhorias, principalmente no que tange o efeito longitudinal sobre a mudança de atitude e de comportamento, lacuna identificada também em outros tipos de programas de prevenção à violência no namoro (Cornelius, \& Resseguie, 2007).

O exame da literatura corrente sugere que programas desenhados para prevenir a violência no namoro não devem focar somente no desafio às atitudes e crenças que suportam tais práticas como algo normal e aceitável. As evidências favoráveis ao uso da educação por pares na prevenção à violência no namoro indicam que o ensino de habilidades de vida (Murta et al., 2013b), habilidades de resistência aos pares (Wolfe et al., 2012), habilidades de resolução de conflitos (Warthe et al., 2013) e habilidades de autoeficácia (Weisz, \& Black, 2008) são alternativas úteis para lidar nesse contexto. Portanto, dar oportunidade aos adolescentes de aprender e praticar tais habilidades parece ser uma forte tendência associada a resultados positivos em estratégias de prevenção à violência no namoro e promoção de relacionamentos saudáveis com base na educação por pares (Ball et al., 2009). 


\section{Referências}

Ackard, D. M., Eisenberg, M. E., \& Neumark-Sztainer, D. (2007). Long-term impact of adolescent dating violence on the behavioral and psychological health of male and memale youth. Journal of Pediatrics, 151(5), 476-81. doi:10.1016/j.jpeds.2007.04.034

Adams, H. L., \&Williams, L. R. (2011). Advice from teens to teens about dating: Implications for healthy relationships. Children and Youth Services Review, 33(2), 254-264. doi:10.1016/j.childyouth.2010.09.008

Adelman, M., \& Kil, S. H. (2007). Dating conflicts: rethinking dating violence and youth conflict. Violence Against Women, 13(12), 1296-1318. doi:10.1177/1077801207310800

Anacona, C. A. R. (2008). Prevalencia, factores de riesgo y problemáticas asociadas con la violencia en el noviazgo: una revisión de la literatura. Avances en Psicología Latinoamericana, 26(2), 227-241. Recuperado de http://revistas.urosario.edu.co/index. $\mathrm{php} / \mathrm{apl} /$ article/viewFile/64/56

Antônio, T., Koller, S. H., \& Hokoda, A. (2012). Peer influences on the dating aggression process among Brazilian street youth: a brief report. Journal of Interpersonal Violence, 27(8), 1579-1592. doi:10.1177/0886260511425794

Arriaga, X. B., \& Foshee, V. A. (2004). Adolescent dating violence: do adolescents follow in their friends', or their parents', footsteps? Journal of Interpesonal Violence, 19(2), 162-184. doi:10.1177/0886260503260247

Backett-Milburn, K., \& Wilson, S. (2000). Understanding peer education: insights from a process evaluation. Health Education Research, 15(1), 85-96. doi:10.1093/her/15.1.85

Ball, B., Kering, P. K., \& Rosenbluth, B. (2009). "Like a family but better because you can actually trust each other": the expect respect dating violence prevention program for at-risk youth. Health Promotion Practice, 10(suppl 1), 45S-58S. doi:10.1177/1524839908322115

Banyard, V. L., \& Cross, C. (2008). Consequences of teen dating violence: Understanding intervening variables in ecological context. Violence Against Women, 14(9), 998-1013. doi:10.1177/107780120832205

Capaldi, D. M., Dishion, T. J., Stoolmiller, M., \& Yoerger, K. (2001). Aggression toward female partners by at-risk young men: The contribution of male adolescent friendships. Developmental Psychology, 37(1), 61-73.

Connolly, J., Furman, W., \& Konarski, R. (2000). The role of peers in the emergence of heterosexual romantic relationships in adolescence. Child Development, 71(5), 1395-1408. Recuperado de https://www.jstor. org/stable/1131981?seq=1\#page_scan_tab_contents

Cornelius, T. L., \& Rosseguie, N. (2007). Primary and secondary prevention programs for dating violence: Areview of the literature. AggressionandViolentBehavior, 12(3), 364-375. doi:10.1016/j.avb.2006.09.006

Dalton, J. H., Elias, M. J., \& Wandersman, A. (2007). Community psychology: linking individuals and communities. Belmont, CA: Thomsom Wadsworth.

Foshee, V. A., Benefield, T. S., Reves, H. L., Ennett, S. T., Faris, R., Chang, L. Y. et al. (2013). The peer context and the development of the perpetration of adolescent dating violence. Journal Youth Adolescence, 42(4), 471-486. doi:10.1007/s10964-013-9915-7

Foshee, V. F., \& Langwick, S. (2010). SafeDates: an adolescent dating abusive prevention curriculum (2nd ed). Minnesota: Hazelden Foundation.

Kinsfogel, K. M.; \& Grych, J. H. (2004). Interparental conflict and cdolescent dating relationships: integrating cognitive, emotional, and peer influences. Journal of Family Psychology, 18(3), 505-515. doi:10.1037/0893-3200.18.3.505

Latané, B., \& Darley, J. M. (1968). Group inhibition of bystander intervention in emergencies. Journal of Experimental Social Psychology, 10(3), 215-221. doi:10.1037/h0026570

Leadbeater, B. J., Banister, E. M., Ellis, W. E., \& Yeung, R. (2008). Victimization and relational aggression in adolescent romantic relationships: the influence of parental and peer behaviors, and individual adjustment. Journal Youth Adolescence, 37(3), 359-372. doi:10.1007/s10964-007-9269-0

Leff, S. (2004). Gaining a better understanding of peer group contributions to dating aggression: implications for prevention and intervention programming: comment on Kinsfogel and Grych (2004). Journal of Family Psichology, 18(3), 516-518.

Makepeace, J.M. (1981). Courtship violence among college students. Family Relations, 30(1), 97-102. doi: $10.2307 / 584242$

Miller, S., Gorman-Smith, D., Sullivan, T., Orpinas, P., \& Simon, T. R. (2009). Parent and peer predictors of physical dating violence perpetration in early adolescence: tests of moderation and gender differences. Journal ofClinical Child \& Adolescent Psychology, 38(4), 538-550. doi:10.1080/15374410902976270 
Murta, S. G., Santos, B. R. P., Martins, C.P. S., \& Oliveira, B. (2013a). Prevenção primária à violência no namoro: uma revisão de literatura. Contextos Clínicos, 6(2), 117-131. doi:10.4013/ctc.2013.62.05

Murta, S. G., Santos, B. R. P., Nobre, L. A., Araújo, I. F., Miranda, A. A.V.M., Rodrigues, I. O. etal. (2013b). Prevenção à violência no namoro e promoção de habilidades de vida em adolescentes. Psicologia USP, 24(2), 263-268. doi:10.1590/S0103-65642013000200005

Murta, S. G., Santos, B. R. P., Nobre, L. A., Oliveira, S. A., Diniz, G. R. S., Rodrigues, I. O. et al. (2011). Diferenciando baladas de ciladas: um guia para o empoderamento de adolescentes em relacionamentos íntimos. Brasília, DF: Letras Livres.

Njaine, K., Oliveira, Q. B. M., Ribeiro, F. M. L., Minayo, M. C. S., \& Bodstein, R. (2011). Prevenção da violência nas relações afetivo-sexuais. In M. C. S. Minayo, S. G. Assis, \& K. Njaine (Orgs.), Amor e violência: um paradoxo das relações de namoro e do "ficar" entre jovens brasileiros (pp. 183-205). Rio de Janeiro, RJ: Editora Fiocruz.

O'Keefe. (2005). Teen dating violence: a review of risk factors and prevention efforts. Harrisburg, PA: VAWnet, National Resource Center on Domestic Violence.

Oliveira, Q. B. M., Assis, S. G., Njaine, K., \& Oliveira, R. V. C. (2011). Violência nas relações afetivo-sexuais. In M. C. S. Minayo, S. G. Assis, \& K. Njaine (Orgs.), Amor e violência: um paradoxo das relações de namoro e do "ficar" entre jovens brasileiros (pp. 87-139). Rio de Janeiro: Editora Fiocruz.

Olsen, J. P., \& Parra, G. R., \& Bennett, S. A. (2010). Predicting violence in romantic relationships during adolescence and emerging adulthood: a critical review of the mechanisms by which familial and peer influences operate. Clinical Psychology Review, 30(4), 411-422. doi:10.1016/j.cpr.2010.02.002

Paciorek, L. B., Hokoda, A., \& Herbst, M. T. (2003). Peer education intervention addressing teen dating violence: the perspectives of the adolescent peer educators. Family Violence \& Sexual Assault Bulletin, 19(4), 11-19.

Rizzo, C. J. (2009). Family and peer contexts shape teen perceptions of dating violence. The Brown University Child an Adolescent Behavior Letter, 25(7), 4-6.

Ruiz, J., Expósito, F., \& Bonache, H. (2010). Adolescent witnesses in cases of teen dating violence: an analysis of peer responses. The European Journal of Psychology Applied to Legal Context, 2(1), 37-53.
Schwartz, J. P., Griffin, L. D., Russel, M. M., \& Frontaura-Duck. (2006). Prevention of dating violence on college campuses: an innovative program. Journal of College Counseling, 9(1), 90-96. doi:10.1002/j.2161-1882.2006.tb00096.x

Shorey, R. C., Zucosky, H., Brasfield, H., Febres, J., Cornelius, T. L., Sage, C. et al. (2012). Dating violence prevention programming: directions for future interventions. Aggression and Violent Behavior, 17(4), 289-296. doi:10.1016/j.avb.2012.03.001

Soares, J. S. F., Lopes, M. J. M., \& Njaine, K. (2013). Violência nos relacionamentos afetivo-sexuais entre adolescentes de Porto Alegre, Rio Grande do Sul, Brasil: busca de ajuda e rede de apoio. Cadernos de Saúde Pública, 29(6), 1121-1130. doi:10.1590/S0102-311X2013000600009

Sullivan, T. N., Masho, S. W., Helms, S. W., Erwin, E. H., Farrell, A. D., \& Taylor, K. A. (2012). Individual, peer, and family factors influencing urban African American adolescents' responses to problem dating situations. Journal of Child and Family Studies, 21(4), 691-704. doi:10.1007/s10826-011-9521-9

Turner, C. J. (2006). Using peers to influence dating relationships: An evaluation of a dating violence prevention program. In Annual Meeting of the American Society of Criminology (ASC), Los Angeles, CA. Vagi, K. J., Rothman, E. F., Latzman, N. E., Tharp, A. T., Hall, D. M., \& Breiding, M. J. (2013). Beyond correlates: a review of risk and protective factors for adolescent dating violence perpetration. Journal Youth Adolecence, 42(4), 633-649. doi:10.1007/s10964-013-9907-7

Warthe, D. G., Kostouros, P., Carter-Snell, C., \& Tutty, L. M. (2013). Stepping up: a peer-to-peer dating violenceprevention projet on a post-secondary campus. International Journal of Child, Youth and Family Studies, 4(1),100-118. doi:10.18357/ijcyfs41201311848

Weisz, A. N., \& Black, B. M. (2010). Peer education and leadership in dating violence prevention: strengths and challenges. Journal of Aggression, Maltreatment \& Trauma, 19(6), 641-660. doi:10.1080/10926771.2010.502089

Weisz, A. N., \& Black, B. M. (2008). Peer intervention in dating violence: beliefs of African-American middle school adolescents. Journal of Ethnic \& Cultural Diversity in Social Work, 17(2), 177-196. doi:10.1080/15313200801947223 
Weisz, J. R., Sandler, I. N., Durlak, J. A., \& Anton, B. S. (2005). Promoting and protecting youth mental health through evidence-based prevention and treatment. American Psychologist, 60(6), 628-648. doi:10.1037/0003-066X.60.6.628

Wolfe, D. A., Crooks, C. V., Chiodo, D., Hughes, R., \& Ellis, W. (2012). Observations of adolescent peer resistance skills following a classroom-based healthy relationship program: a post-intervention comparison. Prevention Science, 13(2), 196-205. doi:10.1007/s11121-011-0256-Z

Zimmer-Gembeck, M. J. (2002). The development of romantic relationships and adaptations in the system of peer relationships. Journal of Adolescent Health, 31(6 suppl), 216-225. doi:10.1016/S1054-139X(02)00504-9

\section{Karine Brito dos Santos}

Doutora pela Universidade de Brasília, Brasília-DF. Brasil. E-mail: karine.unb@gmail.com

Sheila Giardini Murta

Doutora pela Universidade de Brasília, Brasília-DF. Brasil.

E-mail: giardini@unb.br
Endereço para envio de correspondência:

Rua Osvaldo Goch, 1190, bloco 19, apto. 1922, Jardim Bela Vista.

Brasília - DF. Brasil.

Recebido 05/03/2014

Aprovado 11/11/2016

Received 03/05/2014

Approved 11/11/2016

Recibido 05/03/2014

Aceptado 11/11/2016

Como citar: Santos, K. B., \& Murta, S. G. (2016). Influência dos pares e educação por pares na prevenção à violência no namoro. Psicologia: Ciência e Profissão, 36(4): 787-800. doi:10.1590/1982-3703000272014

How to cite: Santos, K. B., \& Murta, S. G. (2016). Peer influence and peer education in dating violence prevention. Psicologia: Ciência e Profissão, 36(4): 787-800. doi:10.1590/1982-3703000272014

Cómo citar: Santos, K. B., \& Murta, S. G. (2016).Influencia de los pares y la educación entre pares en la prevención de la violencia en el noviazgo. Psicologia: Ciência e Profissão, 36(4): 787-800. doi:10.1590/1982-3703000272014 